\title{
Incidents and Complications in Laparoscopic Cholecystectomy: A Retrospective Analysis of 336 Cases
}

\author{
OP Gupta ${ }^{1}$, Salamat Khan ${ }^{2}$ \\ ${ }^{1}$ Professor, Department of Surgery, PIMS, Banthra, Lucknow, ${ }^{2}$ Associate Professor, Department of Surgery, PIMS, Bantthra, \\ Lucknow, India
}

Corresponding author: Dr. Salamat Khan, Associate Professor, department of Surgery, PIMS, Banthra, Lucknow, India

DOI: http://dx.doi.org/10.21276/ijcmsr.2019.4.2.1

How to cite this article: OP Gupta, Salamat Khan. Incidents and complications in laparoscopic cholecystectomy: a retrospective analysis of 336 cases. International Journal of Contemporary Medicine Surgery and Radiology. 2019;4(2):B1-B5.

\section{A B S T R A C T}

Introduction: Laparoscopic cholecystectomy (LC) has become gold standard treatment for symptomatic gall stone disease. Still some incidents and complications are seen more commonly with LC than open cholecystectomy (OC). Various aspects of these complications and their treatment possibilities are discussed. This study was done to analyze the frequency of various complications and possible method of its treatment.

Material and methods: During 2 years 11 months period 336 LCs have been performed at this centers. Of which $88.98 \%$ patients were women and $83.6 \%$ cases were of chronic cholecystitis. Four cases were of hypothyroidism. The age ranged between 11 to 55 years.

Results: Out of 336 cases, $93.75 \%$ (315) cases were successfully operated laparoscopically while 21 (6.25\%) cases developed complications. Of 21 cases, 95.23\% (20) cases developed operative and early postoperative complications. The frequent operative incidents and complications were gall bladder (GB) perforation (15.47\%), stone spillage (10\%), hemorrhage $(2.3 \%)$, common bile duct injuries $(0.89 \%)$. Conversions to open cholecystectomies were done in $2.3 \%$ cases. Most common reason of conversion was acute inflammation with obscure anatomy. The frequent postoperative complications were bile leak, hemorrhage and retained bile duct stone. Two cases required help of minimally invasive procedure. One death was recorded.

Conclusion: The better outcome achieved by LCs permits us to recommend the procedure as suitable alternative in selected patients.

Keywords: Retrospective analysis, incidents, complications, Laparoscopic cholecystectomy

\section{INTRODUCTION}

The prevalence of gall stones ranges from $10-20 \%$ and it is the major cause of morbidity. ${ }^{1}$ Open cholecystectomy has been the cornerstone of the treatment of cholelithiasis for about more than 100 years, since it was introduced by Carl August Langenbuch in $1882 .^{2}$ Other alternative therapies like oral stone dissolution agents and lithotripsy were tried without any intended influence on the treatment of cholelithiasis and therefore seldom used in clinical practice. ${ }^{3,4}$ With the introduction of LC in 1985 by Erich Muhe of Germany, there was gradual change in the treatment of cholelithiasis. Majority of the surgeons and patients accepted this technique and it almost replaced OC. Now this method of treatment of GB stone and inflamed gallbladder has become the $1^{\text {st }}$ choice Worldwide. ${ }^{5-6}$

LC is associated with a number of advantages, but is not without risk as was with OC. Advantages includes early postoperative pain relief, early return to normal activity, decrease hospital stay. ${ }^{7}$ Disadvantages are increase bile duct injuries, longer operative time, longer learning curve and carbon dioxide insufflation side effects. ${ }^{8}$ Some incidents and complications are more frequently associated with LC than $\mathrm{OC}$. This study was done to analyze the frequency of various complications and possible method of its treatment.

\section{MATERIAL AND METHODS}

This was a retrospective study conducted on 336 cases operated laparoscopically for symptomatic gall stone disease at CIMS and hospital between December 2014 and October 2017. Pre-operative diagnosed cases of acute cholecystitis and choledocholithiasis were excluded from the study as these cases were not operated laparoscopically at this center. Both male and female, aged between 11-55 years old with chronic cholecystitis and cholelithisis who were undergone LC were included in this study. The operations were performed with standard four port technique ${ }^{9}$ after hematological, biochemical and radiological investigation and divided into different categories according to peroperative diagnosis as shown in table 1 . These cases were also categorized into different grades according to the level of difficulty encountered during operation as proposed by Cuschieri $^{10}$ (Table-2). Conversion to open operation were done where ever needed. Sub hepatic bile collection 
was treated by ultrasound guided percutaneous drainage. Some cases of bile duct injuries required biliary stenting while others treated by laparotomy with repair and T-tube drainage. Generalized biliary peritonitis were treated with laparotomy and repair. Retained stones were removed by endoscopic sphincterotomy with the help of ERCP.

\section{STATISTICAL ANALYSIS}

Collected data was tabulated, analyzed and following observation were made.

\section{RESULTS}

Thirty-seven (11.01\%) patients were male and 299 (88.98\%) patients were female. Age ranged from 11 to 55 years. Peroperative diagnosis was made as shown in table 1.

\section{Technical difficulties}

Acute cholecystitis, shrunken fibrotic gall bladder, presence of

\begin{tabular}{|l|c|}
\hline Diagnosis & Number of cases (\%) \\
\hline Chronic cholecystitis & $281(83.63 \%)$ \\
\hline Sclero-atrophic cholecystitis & $30(8.92 \%)$ \\
\hline Acute calculous cholecystitis & $14(4.16 \%)$ \\
\hline GB mucocele & $10(2.97 \%)$ \\
\hline $\begin{array}{l}\text { Chronic cholecystitis with } \\
\text { cholecysto-duodenal fistula }\end{array}$ & $01(0.29 \%)$ \\
\hline Total Table-1: Operative Diagnosis \\
\hline \multicolumn{2}{|c|}{ 336(100\%) } \\
\hline
\end{tabular}

\begin{tabular}{|l|c|}
\hline Grade & Number of cases (\%) \\
\hline Grade I & $253(75.29 \%)$ \\
\hline Grade II & $39(11.60 \%)$ \\
\hline Grade III & $36(10.76 \%)$ \\
\hline Grade IV & $08(2.38 \%)$ \\
\hline \multicolumn{2}{|c|}{ Table-2:; Degree of Difficulty at operation } \\
\hline
\end{tabular}

\begin{tabular}{|c|c|}
\hline Grade & Definition \\
\hline 1 & Suppuration at umbilical trocar site on day 5-7 \\
\hline IIA & $\begin{array}{l}\text { Required conservative treatment and prolong hospi- } \\
\text { talization but leave no sequelae. }\end{array}$ \\
\hline IIB & $\begin{array}{l}\text { Complication that require laparotomy or laparo- } \\
\text { scopic re-intervention or endoscopic manoeuvres, } \\
\text { but heal without sequelae. }\end{array}$ \\
\hline III & $\begin{array}{l}\text { Complication other than bile duct stricture, devel- } \\
\text { oping after surgical or lap or reoperation }\end{array}$ \\
\hline IV & Death \\
\hline \multicolumn{2}{|r|}{ Table-3: Early post-operative complication after LC } \\
\hline
\end{tabular}

\begin{tabular}{|l|l|c|}
\hline \multirow{3}{*}{$\begin{array}{l}\text { Obligatory } \\
\text { conversions }\end{array}$} & CBD injury & 03 \\
\cline { 2 - 3 } & $\begin{array}{l}\text { Biliary leak from cystic duct } \\
\text { stump }\end{array}$ & 01 \\
\cline { 2 - 3 } Elective conversions & Pericholecystitis & 01 \\
\hline & Scleroatrophic cholecystitis & 01 \\
\cline { 2 - 3 } & Cholecysto-duodenal fistula & 01 \\
\cline { 2 - 3 } & $\begin{array}{l}\text { Technical reason (sword } \\
\text { fighting) }\end{array}$ & 01 \\
\hline \multicolumn{2}{|c|}{ Table-4: Causes of conversion (8 cases, 2.3\%) } \\
\hline
\end{tabular}

cirrhosis and long duration and uncontrolled hypothyroidism caused difficulty in particular. Some required conversion operation. Great difficulties were associated with Cuschieri's grade III and IV, male sex, presence of inflammatory syndrome and hypothyroidism. Grade III and IV difficulties were observed in $13.65 \%$ cases and patients with history of fever with biliary colic and increased thickness of GB wall reported on ultrasonography. Increase of wall thickness is either caused by inflammation or adhesion of omentum to gall bladder (Table 2).

\section{Intraoperative incidents and accidents}

Perforation of GB, gall stone spillage, hemorrhage, bile duct injury and conversion to open cholecystectomy were observed and discussed.

Perforation of GB and gall stone spillage were the common problem during LC. It occurred either during dissection or extraction of GB in 52(15.47\%) cases. The incident of stone spill was more difficult than serious, especially when removal of lost gall stones from the peritoneal cavity necessary. This incident prolongs operation time.

Hemorrhage from cystic artery was not observed but bleeding from gall bladder bed were noted in 18 (5.35\%) cases especially in acute cholecystitis. In all cases hemostasis were achieved by mono or bipolar cauterization laparoscopically. None of the patient required hemostatic patch or conversion. Bile duct injuries were noted in $3(0.89 \%)$ cases peroperatively. These cases were converted and bile duct injuries were treated either primary repair (1 case) or repair with T-tube insertion. Peritoneum was drained in all cases by sub-hepatic drain. Patient with primary biliary repair who developed sub hepatic bile collection which was treated by endoscopic biliary stenting and USG guided PCD. All these cases were recovered. There was no case of right hepatic duct injury in this series.

Biliary peritonitis was noted in 2 cases. First case was due to bile duct injury and second case was due to leakage from cystic duct stump. In second case stone was removed by cutting Hartman's pouch and sutured by continuous running suture intracorporeally. But it leaked and treated by laparotomy with re-suturing of stump and drainage. Both cases were of acute cholecystitis with impacted stone at Hartman's pouch. Both patients were recovered.

Conversion operation were performed in $8(2.3 \%)$ cases (Table 4). Of 8 cases, 3 were of CBD injuries, one case of each of bile leak from cystic duct stump, pericholecystitis, Scleroatrophic cholecystitis, cholecysto-duodenal fistula and technical problem (sword fighting). The commonest reason of conversion was acute cholecystitis with impacted stone in Hartman's pouch with obscured anatomy. Two cases of CBD injuries were associated with acute cholecystitis and one cases associated with Scleroatrophic cholecystitis. In scleroatrophic cholecystitis, injury of CBD occurred due to ligation in confusion between cystic duct and CBD. All cases were recovered.

\section{Early postoperative complications (Table 5)}

Complications associated with LCs were graded based on Clavien's classification ${ }^{11}$ (Table 3). Ten cases (2.9\%) were of grade I. These cases were cured with local treatment in few 


\begin{tabular}{|l|c|c|c|c|c|}
\hline Complications & $\begin{array}{c}\text { Conservative } \\
\text { treatment }\end{array}$ & $\begin{array}{c}\text { Minimally } \\
\text { invasive } \\
\text { treatment }\end{array}$ & $\begin{array}{c}\text { Open } \\
\text { surgery }\end{array}$ & Others & Total \\
\hline Port site hematoma and infection & 10 & - & - & - & 10 \\
\hline Bile leak & 01 & 02 & - & - & 03 \\
\hline Choleperitoneum & - & - & 01 & - & 01 \\
\hline Postoperative hemorrhage (except port wound) & 04 & - & - & - & 04 \\
\hline Retained duct stone & - & 01 & - & - & 01 \\
\hline Umbilical hernia & 01 & - & - & - & 01 \\
\hline Death & - & - & - & 01 & 01 \\
\hline Total & 16 (76.19\%) & $03(14.28 \%)$ & $01(4.76 \%)$ & $01(4.76)$ & $21(100 \%)$ \\
\hline \multicolumn{2}{|c|}{ Table-5: Early and late post-operative complications (21 cases, 6.25\%) and their treatment } \\
\hline
\end{tabular}

days. This complication was frequently associated with acute cholecystitis (8 of 10 cases) and fatty patients ( 2 of 10 cases). There were 6 cases of grade IIA complication. Of 6 cases 3 cases were of biliary leak and 3 cases of hemorrhage. All the cases were of acute cholecystitis. Hemorrhage and biliary leak stopped spontaneously within 3-5 days. Two cases were of grade IIB complications. One case was managed by endoscopic biliary stenting and USG guided PCD of sub-hepatic biliary collection while another case was under went laparotomy with re-suturing of Hartman's stump. Both cases were recovered well. These cases were of acute cholecystitis with impacted stone at Hartman's pouch. No case was recorded of grade III while one case was of grade IV. This case was hypothyroidism which diagnosis missed before operation and patient was drug defaulter. Patient after surgery went into irreversible shock and died.

Four LCs were done on hypothyroid patients. Preoperative diagnosis was known in 2 cases while it was missed in 2 cases. There was aggravation of neuropsychiatric symptoms in early post-operative period in 2 cases and one case died. Out of 4 patients, 3 cases recovered.

\section{Late postoperative complications}

On follow-up, up to 1 year, one case of residual calculi observed. Per-operatively there was no clinical or radiologic evidence of ductal stone. The calculi were extracted with endoscopic sphincterotomy. Umbilical hernia was present in one case. This developed in the case who had port site infection. Patient was counselled for operation but patient refused.

\section{DISCUSSION}

Incidents and complications associated with LCs should neither overestimated nor underestimated. This operative procedure not easy. The surgical outcome can be improved by good skill and proper selection of cases especially in the beginning. Reports of recent data show a lower morbidity rates (LC: OC:1.9\%:7.7\%) and mortality rates (LC: OC: 1\%:5\%) in LC in contrast to initial reports. ${ }^{12-16}$

Certain important conditions like acute cholecystitis, shrunken and fibrotic GB, cirrhosis and obesity increases the risk of complications. Pericholecystitis changes local anatomy that causes loss of dissection plane between GB and liver and difficulty in identifying CBD and structures of Calot's triangle. Often it is impossible to perform duct first method cholecystectomy in most cases. Therefore, there is risk of injury to the CBD and liver parenchyma. This increases postoperative chances of hemorrhage from liver, biliary leak and sub hepatic collection and abscess formation, if not drained. Fibrotic gall bladder has contracted GB and short cystic duct. Excessive fundal traction may cause CBD tenting and injury. Cirrhosis with regenerating nodule extending into GB bed may pose difficulty and may be injured. In a few obese cases marked fatty infiltration of the Calot's triangle increases chances of complications. In spite of this, the maximum advantage of LC goes to these patients due to low rate of wound infection, wound dehiscence, and incisional hernia.

Hemorrhage, bile duct injury, choleperitoneum, sub hepatic collection and abscess are the main concern with LC. Hemorrhage during LCs can occur from, port wound, cystic artery, gall bladder bed and omentum. Per-operative arterial hemorrhage is one of the reason for conversion. ${ }^{13,14,17,18}$ In this study one case of port site bleeding encountered which was treated by cauterization. Some authors have observed that panic reaction of the surgeons is more dangerous than bleeding. Losing patience and blind application of clip or cautery hook, can cause severe injury to the bile duct. Grasping of bleeder provides good temporary hemostasis followed by clipping or bipolar cautery can be done.

Hemorrhage from gall bladder bed commonly encountered in acute cholecystitis, shrunken GB, cirrhosis and in partial cholecystectomy. ${ }^{17-19}$ Hemostasis was achieved in majority of these cases by laparoscopic electro-cauterization. ${ }^{17-19}$ In the present study, hemostasis was achieved from cauterization in all cases and did not required hemostatic patch or conversion as reported by previous workers. ${ }^{17}$

Injury to extrahepatic bile duct which can occur at any level apart from injury of duct of Luschka if present. ${ }^{20-23}$ More serious problem is associated with injury to the main extra hepatic ductal system. This type of injury is more frequently associated with $1 \%$ cases in LC than OC $(0.5 \%)^{10,13,17,21,29}$ This difference is statistically not significant but clinically troublesome. Acute cholecystitis with difficult anatomy and inexperience surgeon were the two main reason identified in a study analyzed 15 bile duct injuries. ${ }^{27}$ We have also come across this situation in 2 cases. we resorted to conversion. Lack of surgeon's experience is the $2^{\text {nd }}$ factor for ductal injury in the beginning observed in a study where $1.7 \%$ injuries were reported. These incidences occurred among the first 1015 laparoscopic operations. ${ }^{15}$ 
Duct of Luschka may be opened if present in the GB bed. It is reported in 3-5\% individuals in a postmortem study. ${ }^{20}$ Knowledge of this duct will decrease the incidence of morbidity. During surgery this can be suspected with appearance of bile in GB fossa without GB perforation. If it is encountered it should be either clipped or ligated. Some of the studies have reported biliary peritonitis due to leakage of bile from these ducts. If bile leakage is $>500$ $\mathrm{mL} / 24$ hours and persists in the early postoperative period, endoscopic sphincterotomy or trans papillary stenting is recommended. ${ }^{23-26}$ This will decompress biliary ductal system and gradually stop bile leak, thus avoid reoperation. If doubt arises and duct is not found during operation sub hepatic drain should be placed. Biliary peritonitis without sub hepatic drain are either treated by USG guided PCD at well-equipped centre with or without sphincterotomy or biliary stenting. Laparotomy with peritoneal drainage are done where advance facilities are not available. We have two case of postoperative sub hepatic peritoneal collection. One case was managed by USG guided PCD along with confirmation of any major duct injury by MRCP and second case was treated with USG guided PCD with endoscopic biliary stenting. Gradually bile leak stopped and both patients recovered. The use of similar technique along with laparoscopic reintervention with clipping of duct, were also reported. Many of these cases were in whom lack dissection plane between GB and liver and often the liver capsule has been damaged ${ }^{17,23-25}$, Choleperitoneum after OC from cystic duct is rare, but this is more frequent in LCs. Some studies have reported $50 \%(17 / 34)$ cases with biliary complication. ${ }^{22}$ We have encountered one case of bile leak from cystic duct stump. This case was of empyema GB with impacted stone in Hartman's pouch which was removed by cutting it. The cut end was sutured intracorporeally but leaked. This case was managed by laparotomy and re-suturing of the stump.

Ligation or clipping in LC is specific to CBD. It occurs during application of first clip to the cystic duct. In our series ligation of $\mathrm{CBD}$ occurred in one case with shrunken and fibrotic gall bladder but on suspicion due to its size, conversion was done and corrected. Clipping or ligation near to the Hartman's pouch may leave long cystic duct stump. Leaving long cystic duct stump without stone is not the true cause of post cholecystectomy syndrome. ${ }^{30}$

Bile leakage and bleeding is the reason of sub-hepatic abscess formation in cases of acute cholecystitis as reported in some studies. ${ }^{15,17}$ We have not observed a single case in this series. It could be because of a few cases of acute cholecystitis.

Hemorrhage and bile leak from GB bed were 2.7 times more in LC, with no sub-hepatic abscess in OC. ${ }^{17,31}$ This is because of routine practice of peritoneal suturing or placing sub-hepatic drain. ${ }^{31}$ Suturing of peritoneum is commonly practiced after OC which is not possible in LC might be the reason of increase incidence of this complication. ${ }^{31}$

Retained bile duct stone was not observed at early postoperative period but one case was diagnosed after 3 months of LC in this series. It was extracted by endoscopic sphincterotomy. Bile duct calculi can be suspected peroperatively by presence of multiple calculi, dilated cystic and bile duct. Full investigation for CBD not possible at operation due to local inflammation or hypertrophied Heister's valve. Endoscopic sphincterotomy with extraction of stone done in both early and late diagnosed cases. ${ }^{18}$

Surgical stress of laparoscopic surgery can alter thyroid function and significantly decrease production of T3 and T4 in normal functioning thyroid patients during first 24 hours after surgery. ${ }^{32}$ In hypothyroid patient's there may be further decrease in production of thyroid hormone. Due to this, complications like neuropsychiatric symptoms and hypotension are significantly increased. ${ }^{33}$ In the present study 3 cases developed hypothermia were treated by warming and intravenous corticosteroid and one case developed irreversible shock and died.

Twenty-one (6.25\%) patients developed complications. Of 21 patients, conversion was done in $8(40 \%)$, endoscopic manoeuveres in 2 cases, USG guided PCD in 2 cases.

\section{CONCLUSION}

The better outcome achieved by LCs permits us to recommend the procedure as suitable alternative in selected patients.

\section{REFERENCES}

1. Doke A, Gadekar J, Dash N,Unawane S. A comparative study between open versus laparoscopic cholecystectomy. Sch J AppMed Sci, 2016;4(1):57-61.

2. Gadacz TR, Talamini MA,. Traditional versus Laparoscopic Cholecystectomy .Am J Surg. 1999;161(2):336-8.

3. Villanova N, Bazzoli F, Taroni F, Frabboni R, et al. Gall stone recurrence after successful oral bile acid treatment. A 12 year follow -up study and evaluation of long term post dissolution treatment. Gastroenterol.1989;97(6):726-31.

4. Della Bianca P, Bonvin B. Lithotrypsy of biliary calculi by shock waves. Current possibilities and perspectives. Helv Chir Acta.1990;56(3):913-6.

5. McSherry CK. Open cholecystectomy. Am J Surg. 1993;165(2):435-9.

6. Ji W,Li LT JS. Role of Laparoscopic subtotal cholecystectomy in treatment of complicated cholecystitis.Hepatobilpancreat DisInt. 2006;5(6): 5849.

7. Strasberg SM. Clinical practice acute calculous cholecystitis.New England Journal .2011;358(26):2804.

8. Paulino-Netto A.A review of 391 selected open cholecystectomies for comparison with laparoscopic cholecystectomy. Am J Surg. 1993;166(5):71-3

9. Zucker KA. Surgical Laparoscopy. St. Louis: Quality Publishing Inc., 1991;143-82

10. Cuschieri A, Berci G. Laparoscopic Biliary Surgery. Oxford: Blackwell Scientific Publication 1992;96116,134-42

11. Clavien PA, Sanabria JR, Strasbrg SM. Proposed classification of complications of surgery with examples of utility in cholecystectomy. Surgery 1992;111(3): 51826.

12. Deziel DJ, Milikan KW, Economou SG, et al. Complications of laparoscopic cholecystectomy: a national survey of 4292 hospitals and analysis of 77607 
cases. Am J. Surg 1993; 165(1):9-14.

13. Baily RW, Zucker KA, Flower JL et al. Laparoscopic cholecystectomy Ann Surg 1991;214(4):531-41.

14. Febre JM, Fagot H, Domergne J, et al. Laparoscopic cholecystectomy in complicated cholelithiasis. Surg Endosc 1994; 8(3): 1590-2.

15. Hunang SM, Wu CW, Mong HT, et al. Bile duct injury and bile leakage in laparoscopic cholecystectomy. $\mathrm{Br} \mathrm{J}$ Surg 1993;80(2): 1590-2

16. Jatko G, Lisborg PH, Perti Am, et al. Multivariate comparison of complications after laparoscopic cholecystectomy and open cholecystectomy. Ann Surg 1995; 221(5):1129-97.

17. Duca S, Bala N, Al-Hajjar N, et al. Laparoscopic cholecystectomy: incidents and complications. A retrospective analysis of 9542 consecutive laparoscopic operations. HPB 2003;5(3): 152-58.

18. Rooh-ul-Auquim, Qutab-e-alam Jan, Zarin M, et al. Complication of laparoscopic cholecystectomy. World Journal of Laparoscopic Surgery 2008:1(1);1-5.

19. Wolfe BM, Gardiner BN, Leary BF, et al. Endoscopic cholecystectomy. Arch Surg 1991; 126(3):1129-97.

20. Klotz HP, Schlump F, Largiader F. Injury to an accessory bile duct during laparoscopic cholecystectomy. Surg Laprosc Endosc 1992; 2(2):317-20.

21. Eldman DS. Bile leak from liver bed following laparoscopic cholecystectomy. Surg Endosc 1994;8(1): 205-7.

22. Woods MS, Shellito JL, Santoscopy GS, et al. Cystic duct leaks in laparoscopic cholecystectomy. Am J Surg 1994;168.

23. Bedogni G, Mortilla MG, Ricci E, et al. The role of endoscopic treatment of early biliary complications of laparoscopic cholecystectomy. In: Meimro M(ed) Laparoscopic Surgery. Milan: Ed Massori, 1994;145-88.

24. Brandbur JJ, Kozarek RA. Endoscopic repair of bile leaks after laparoscopic cholecystectomy. Semin Ultrasound CT MRI 1993;14(3): 375-80.

25. Davids PHP, Rauws EAJ, Tycat GNJ. Postoperative bile leakage: endoscopic management. Gut 1992; 33(4):1118-22.

26. Kozarek RA. Endoscopic treatment of biliary injuries. Gastroenterol Clin North Am 1993; 3(3):261-70.

27. Schol EPG, Go PM, Gouma DJ. Risk factors for bile duct injury in laparoscopic cholecystectomy; analysis of 49 cases. Br J Surg 1994; 81(5):1786-8.

28. Naugebauer E, Sauerland S, Troidl S. Recommendations for evidence based endoscopic surgery. Paris Springer, 2000;36-46.

29. Russel JC, Walsh SJ, Mattie AS, et al. Bile duct injuries 1989-1993. A statewide experience. Connecticut laparoscopic cholecystectomy Registry. Arch Surg 1996; 131(6):382-8.

30. Aanima M, Makela P. The cystic stump and postcholecystectomy syndrome. Ann Chir Gynecol 1981; 70:297-303.

31. Ham JM. Cholecystectomy. In: Blumgart LH (ed). Surgery of liver and Biliary tract. vol. I. Edinburgh: Churchill Livingstone, 1998;559-67.

32. Ali uzunkoy. Laparoscopic surgery effects thyroid function: A short communication Clinic in surgery - surgical oncology 2018;3(4):23-34.

33. Landerson PW, Levin AA, Ridgway EC, et al. Complication of surgery in hypothyroid patients. Am J Med 1984; 77(2): 261-6.

Source of Support: Nil; Conflict of Interest: None

Submitted: 12-03-2019; Accepted: 08-04-2019; Published online: 20-04-2019 